\title{
SYSTEM FOR MONITORING CONTROL IN INDUSTRIAL TeChnological Processes
}

\author{
Alexander Aryskin, Alexei Grigorev, Roman Khelemendik, Maxim Petra- \\ kov, Valentin Pryanichnikov \& Radomir Tarasov
}
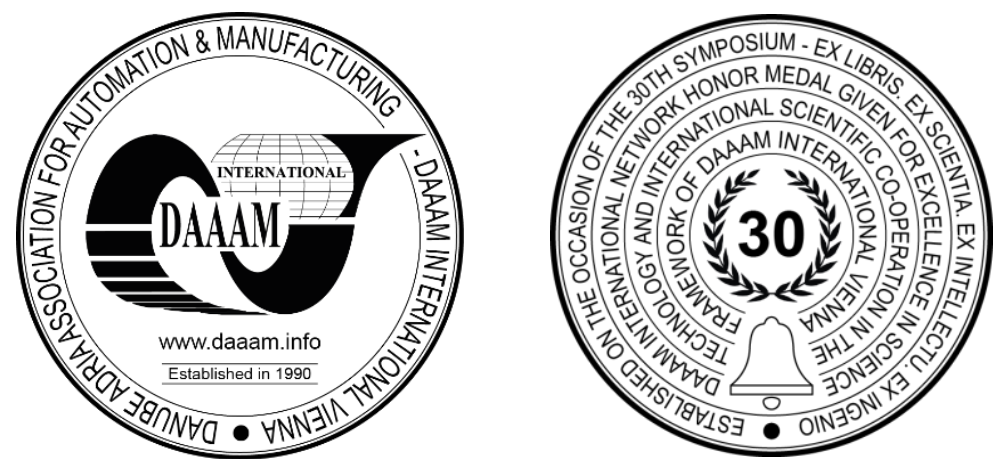

This Publication has to be referred as: Aryskin, A[lexander]; Grigorev, A[leksei]; Khelemendik, R[oman]; Petrakov, M[axim]; Pryanichnikov, V[alentin] \& Tarasov, R[adomir] (2020). System for Monitoring and Control in Industrial Technological Processes, Proceedings of the 31st DAAAM International Symposium, pp.0644-0649, B. Katalinic (Ed.), Published by DAAAM International, ISBN 978-3-902734-29-7, ISSN 1726-9679, Vienna, Austria DOI: $10.2507 / 31$ st.daaam.proceedings.089

\begin{abstract}
New technological solutions led the industrial society to new methods of collecting, processing, storing, and transmitting a large amount of information. This factor is directly related to the fact, that now they are moving away from partial automation of mechanisms to the tasks of combining the entire production process into a single information cycle of control and monitoring. Automated systems for logical control of technological processes were built to perform simple tasks, but with the increase in production capacity, the complexity of control also increased, which led increasing the number of information links and information flows [1-3]. This, in turn, led to the need for modularity, flexibility, expansion of software and logical capabilities, increased fault tolerance, and scalability [4-6]. When such requirements are met, automated production systems are one step closer to "smart production", and for the full implementation of the "Industry 4.0" concept. It is necessary to combine all digital streams and data into a single systematized database for processing Big Data. In KIAM, on the base of the International laboratory "Sensorika" and partners, a processing control system has been developed and implemented, capable to handle large data loops within itself. Specialized application program has been created, that allows simultaneous monitoring of all control actions emanating from the operator, technologist and rigid control logic with the ability to analyze for contradictions, thereby eliminating the occurrence of emergencies, in turn. It allows you to keep the risk of equipment failure at the necessary low level. The role of the operator in this process system is to passively monitor the displayed data, that occurs in the shop in real time, on the monitor, as well as the selection of necessary recipes that are created automatically and stored in the database. In addition to the control system was implemented in software for database, preserving all actions of the operator, as well as storage of recipes and recording new recipes for "intelligent system" monitoring all components and assemblies of the processes.
\end{abstract}

Keywords: monitoring and control of technological production processes; extensive logical analysis; Industry 4.0 implementation; SCADA.

\section{Introduction}

KIAM Russian Academy of sciences in cooperation with International Laboratory "Sensorika" and its' partners have developed and implementing the industrial processes control system capable of internally organizing the large data plumes, as well as a specialized application program for control a real production site [1-9]. 
This software allows you simultaneously monitor all the control actions coming from the operator, technologist and had control logic with the ability to analyze the presence of contradictions, thereby eliminating the occurrence of emergencies. This, in turn, allows you to keep the risks of equipment failure at the necessary low level. The control object system consists of two complexes: transport/molding and synthesis of substances (brewhouse). The operator's role in this technological process is to passively observe the displayed data showing the occurring in the shop in real time, on a monitor, as well as to select the necessary recipes, that are created automatically and stored in the database. Figure 1 shows the operator interface, describing the brewhouse processes (substance synthesis) with controls, reporting, recipe changes and output of emergency status data.

In addition to the control system, so software for a database was implemented, with all operator actions saved, as well as with the storage of recipes and the ability to record new recipes using the "intelligent system" for monitoring the state of all units and aggregates of the "cooking" process.

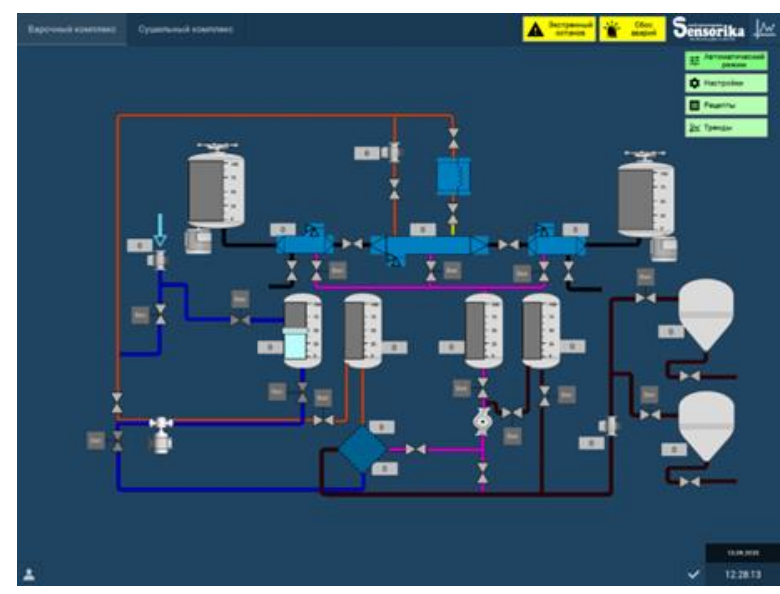

Fig. 1. Complex the synthesis of substances (brewhouse).

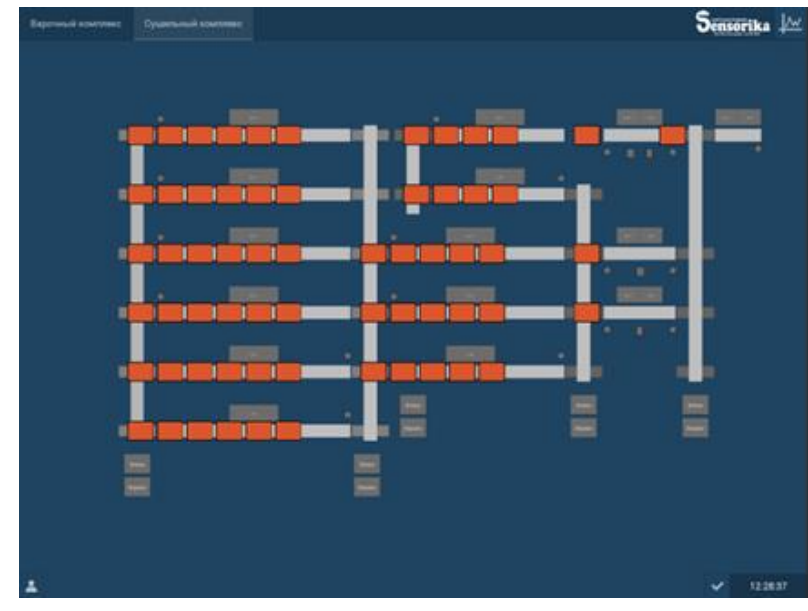

Fig. 2. Transport and molding (drying complex)

Returning to the hardware component of automated production control systems, it should be noted, that the use of expensive feedback actuators in this version of the system is not a mandatory requirement [10-15]. The control logic processes based on an analysis of the whole system, and automatic opening, such as valve (gate valve) can be traced by circumstantial evidence - such as the increase or decrease of water volume in the tank, and changing temperature indicators in the system, etc.

\section{Design of the workshop and control system}

The manufactured raw materials in the brewhouse complex enter the transport and forming drying complex, where the subsequent solidification of raw materials takes place. The drying complex consists of a transportation system of rail tracks with trolleys carrying molding containers for raw materials. Depending on the consistency of raw materials, its drying parameters change, so the drying process for each of the blanks is individual. Figure 2 shows the interface for visualizing the state of the drying shop, with the output of limit switches, as well as the ability to make decisions on controlling the direction of movement of trolleys.

Operational management of all types of productions implies an immediate response to the operator's control actions, especially if this action is associated with an emergency stop of technological processes [16-22]. Operational control can be carried out at the appropriate operator stations, using light fittings and a software package installed on a computer. The software package refers to a SCADA system, that allows the processing of data involved in the technological process.

The created software and hardware implement typical processes, that take place in a significant part of the control systems of smart factories, built on the basis of the Industry-4.0 concept [23-27]. Thus, the data, obtained from the implemented software and hardware tools, are a good example of creating a technological base, a constructive approach to organizing smart industries and other similar industrial applications. Below (Fig. 3) is a variant of the operator's monitors. One monitor shows the visualization of technological processes, while the other displays images from video surveillance cameras. Switching between brewhouse and drying processes is performed in the upper part of the operator's PC working field. 

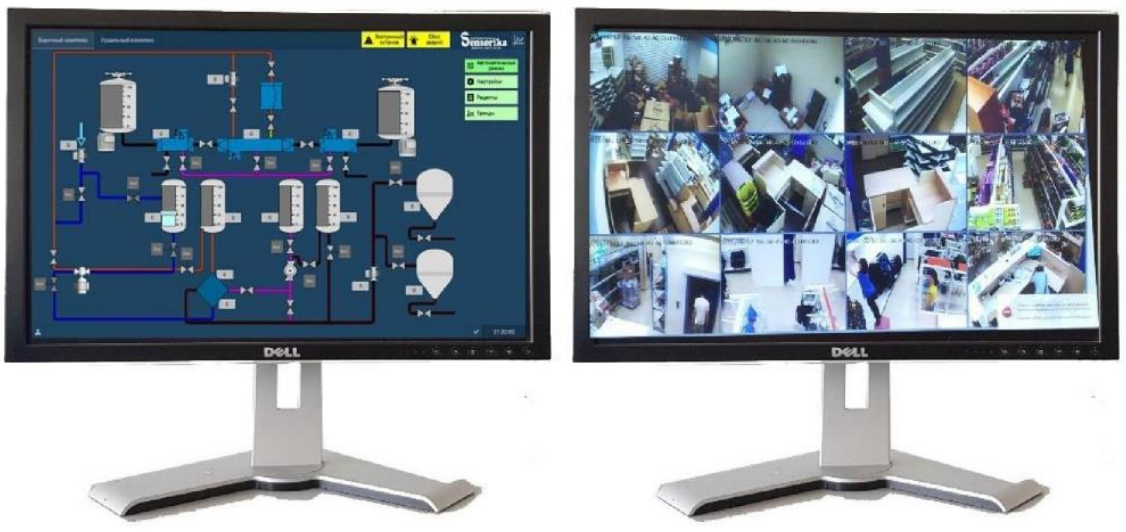

Fig. 3. Interface of the production processes monitoring and control system.

The scheme of organization of the upper level of process control and monitoring is shown in figure 4. It consists of a central server with the function of reserving and duplicating data in real time with operator stations connected to it. Specialized software, that is configured to work within the process system allows you see the output video stream from surveillance cameras, as well as output of SCADA by the system's SCADA interface, with the ability to authorize and set control priorities.

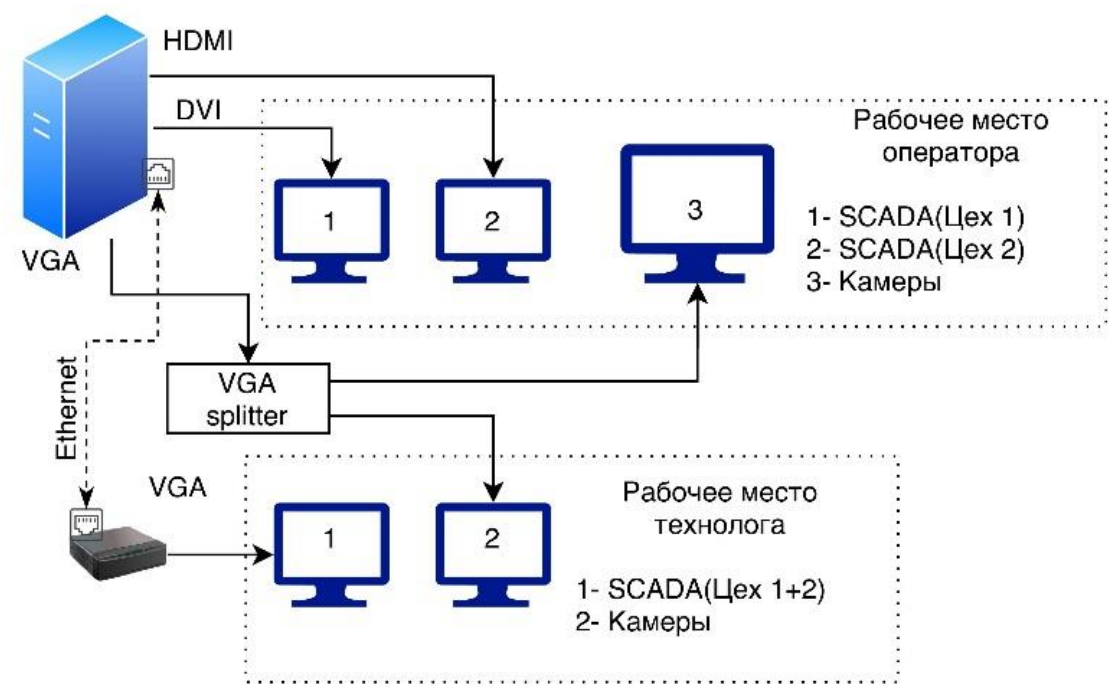

Fig. 4. Diagram of the organization of the top level of control and monitoring

To ensure trouble-free operation of production processes, all control functions and tasks were divided into two parts:

- Planning tasks and eliminating logical contradictions;

- Real-time execution of the software algorithms.

Partial planning of functional movements can be performed through the SCADA system, installed at the operator's station of the upper control level. Thanks to operator stations with SCADA system, it becomes possible to monitor the software forecasts and calculations made, monitor the actual readings of various sensors and issue control signals to the executive elements of the production process, performed using programmable logic controllers [28-31].

Typical in this project are the tasks of managing the preparation of raw materials based on hundreds of recipes, as well as predicting the movement of mechatronic modules on conveyors [32-34]. Thanks to a specialized algorithm, within the framework of this project, it became possible to predict contradictions and emergencies during the execution of the technological process. In the drying complex, on the basis of this algorithm, the motors (around 100 units) are controlled according to the law of trapezoidal change in the speed of movement. Due to the need to take into account many different parameters of mobile trucks/trolleys on conveyor rails (loading, wear of driving parts, etc.), it was necessary to pay special attention, for example, to control and constantly calculate the moments of approach to the areas of acceleration, braking with a given acceleration or moving at a constant speed. The appropriate application package with a process simulation model is implemented/embedded into the system. Thanks to this package, it becomes possible to analyze the states of each mechatronic module in the complex and make adjustments to production scenarios. 


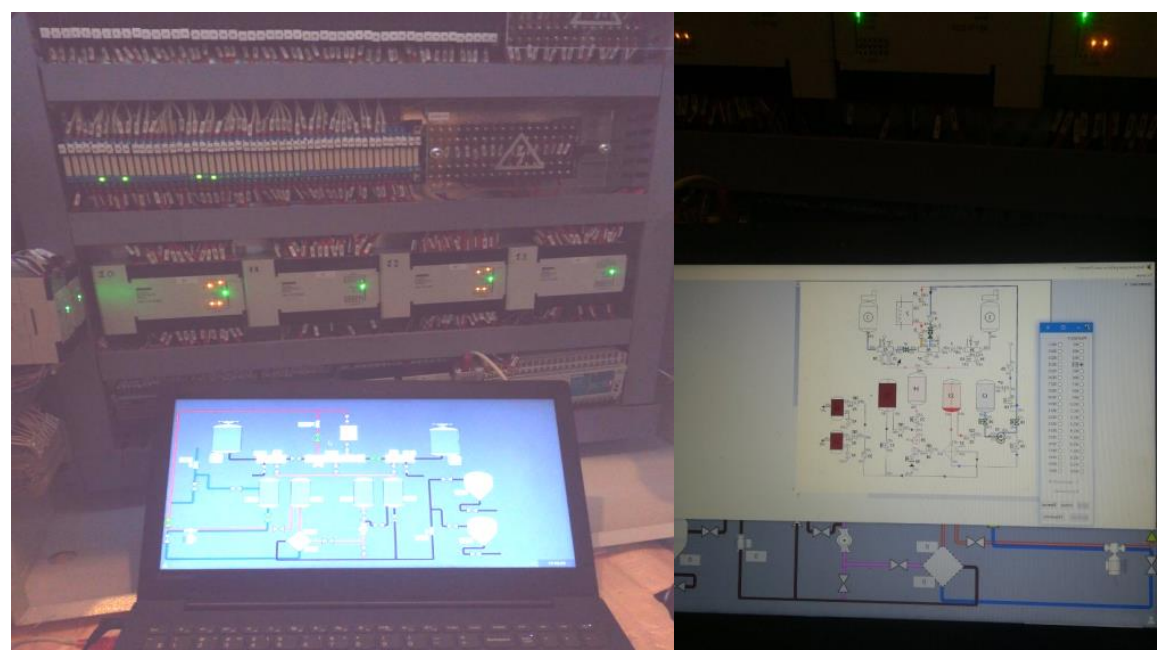

Fig. 5. Test of the algorithm for logical analysis of the technological process of manufacturing and casting finished raw materials into molds.

In accordance with the above, specialists and participants of the KIAM "process automation group" and the International laboratory "Sensorika" were written the algorithm, as well as its analysis based on the logic. This algorithm is written in the Delphi software environment, the test of the algorithm for controlling the brewhouse complex is shown in (Fig. 5).

\section{Design and work of the algorithm and PLC program}

The algorithm of analysis for the presence and elimination of logical contradictions includes a program for constant getting and comparison of the values of readings received from various sensors of the system. To compare this data, we developed a system of Boolean and symbolic tables, which we will present as examples/fragments below. Each sensor reading value is described and analyzed by the Boolean functions. Based on the analysis results, the appropriate value is assigned if FALSE, the system outputs an error message with the appropriate parameters and an early exit from the analysis cycle occurs with the message "the file with sensor parameters was not read". If TRUE, the values received from the sensor are read and updated in the sensor readings field.

The file format with sensor values is as follows: all sensors are divided into 3 types - volume sensors (type designation $-\mathrm{V})$, temperature $(\mathrm{T})$, and pressure $(\mathrm{P})$. Each sensor has two indexes: upper and lower. The upper index is an ordinal number for this type of sensor, while the lower index denotes the object, to which this sensor belongs. For example, $\mathrm{V}^{\wedge} 1 \_1$, the first probe volume refers to $1^{\text {st }}$ to the autoclave, measures (in tonnes), volume of loaded source of the product; $\mathrm{V}^{\wedge} 13 \_1$ - thirteenth the volume sensor, refers to $1^{\text {st }}$ to the autoclave, measures (in liters) volume of water in the autoclave; $\mathrm{T}^{\wedge} 8 \_16$ eighth temperature sensor, measures it in the barrel $16 ; \mathrm{P}^{\wedge} 2 \_3-$ a second pressure sensor, which measures the object 3 to the second autoclave, and so on. There are 36 sensors in total: 17 for volume, 13 for temperature, and 6 for pressure (Fig. 1). Low level is realized on PLC. It stands to mention, that every PLCs have special programs (Fig. 6) to monitor the operation of valves (area a) and sensors (area b) and, of course, there is module for control the connection (area c).
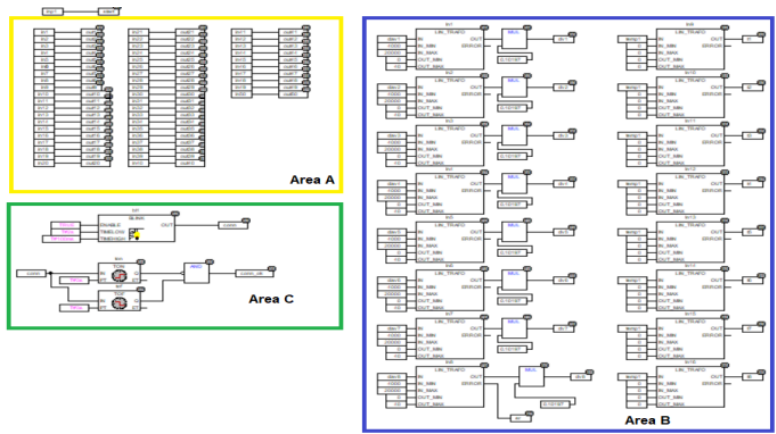

Fig. 6. Programming the PLC models.

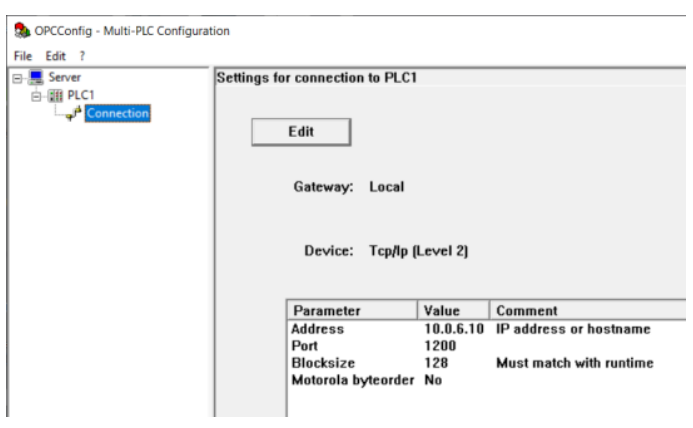

Fig. 7. OPC-server - mechanism of synhronazing.

It is used OPC-server for connecting PLC and SCADA system. It is common way, to connect all PLCs and similar devices with top-level control systems. In figure 7 you can see program window for configuration of OPC-server. Also it was implemented the bridge from OPC-server to Delphi simulation model. 


\section{Conclusion}

To solve the problem of transition to smart digital production, a special system was developed for the generation and control of recipes in production. The system in automatic mode successfully calculates the results of the control algorithm and gives recommendations to the operator and technologist, on the basis of which the automated process is able to work flawlessly and produce high-quality products. The developed algorithm supports the recording of button click events on the central hardware control panel of the workshop for the subsequent generation of recipe programs. The algorithm was tested at an enterprise in the Moscow region as part of work on automating the hardware and software control complex of a robotic industrial line for manufacturing products from innovative materials. In the future, it is planned to introduce a computer vision system for automating product quality control.

\section{References}

[1] Aryskin, A[leksander] A[.]; Bogdanovich, A[lena]; Davydov, O[leg]; Khelemendik, R[oman]; Petrakov, M[axim] \& Pryanichnikov, V[alentin] (2019). Control and Interaction Algorithms for Industrial and Service Robots, Chapter 33 in DAAAM International Scientific Book 2019, pp.377-384, B. Katalinic (Ed.), Published by DAAAM International, ISBN 978-3- 902734-24-2, ISSN 1726-9687, Vienna, Austria DOI: 10.2507/daaam.scibook.2019.33

[2] Pryanichnikov V. E., Chernyshev V. V., Arakantsev V. V., Aryskin A. A., Ksenzenko , A. Ya., Petrakov M. S., Treveskyn A. S., Eprikov S. R. (2019)/ / Intelligent adaptive robots (Special issue of the journal - Informationmeasuring and control systems, vol. 16, no. 12), Moscow: Radiotechnika, vol. 14, no. 1-2, 2019, ISSN 2070-0814, pp. 49-56, DOI 10.18127 / j20700814-201812-05

[3] The principle and methodological foundations of constructing software systems for logical control of technological equipment: abstract dis. ... doctor of technical Sciences: 05.13.06 / Nezhmetdinov Ramil Amirovich; [place of defense: MSTU "STANKIN"]. Moscow, 2020, 39 p. (in Russian).

[4] Aryskin A.A., Ksenzenko A.Ya., Marzanov Yu.S., Prices E.A., Pryanichnikov V.E., Khelemendik R.V., Eprikov S. R. (2017) / Industrial automation with remote access and automatic resolution of logical contradictions for industry 4.0, ekstremal'naja robototekhnika [Extreme robotics]. // Collection of abstracts of the International scientific and technical conference. - Saint Petersburg: Publishing and printing complex "Gangut", 2017. - 272 p., With.190-193. URL: http://er.rtc.ru/images/docs/Sbornik_tezisov_ER_2017.pdf

[5] Khelemendik R.V. (2006). An algorithm for determining satisfiability formulae of computation tree logic and an effective algorithm for constructing derivations of valid formulas from axioms. Mathematical Issues of Cybernetics, no. 15, A collection of papers, ed. by O.B.Lupanov. Moscow: Fizmatlit, 2006, pp. 217-266.

[6] Khelemendik R. V. (2000). Applications of linear and branching time logics. Algorithm for testing satisfiability// Bulletin of the Nizhny Novgorod state University. Mathematical modeling and optimal control. Nizhny Novgorod: Publishing house of the Nizhny Novgorod University, 2000, Vol. 1 (22), Pp. 176-191.

[7] The official Russian-language site of the company "CoDeSys" [electronic resource]: the Official Russian-language site of the company "CoDeSys" - access Mode: http://www.codesys.ru/(accessed 01.01.2020).

[8] The official website of the software product CoDeSys of the company 3S-Smart Software Solution GmbH [electronic resource]: the official website of the software product CoDeSys of the company 3S-Smart Software Solution GmbH-access Mode: https://www.codesys.com/(accessed 01.01.2020).

[9] Official site of the company "ARIES" [electronic resource]: Official site of the company "ARIES" - access Mode: http://www.owen.ru/(accessed 10.01.2020)

[10] Aryskin A.A., Kozak N.V. (2016) / Construction of components of a distributed control system based on a singleBoard raspberry PI2 computer. Materials of the student scientific and practical conference "automation and information technologies (AIT-2016)". First round. Collection of reports, Moscow: MSTU STANKIN, 2016.

[11] Aryskin A.A., Kozak N.V. (2015) / Building a development environment applications of automation single Board computers. Materials of the student scientific and practical conference "automation and information technologies (AIT-2015)". First round. Collection of reports, Moscow: MSTU STANKIN, 2015, Pp. 18-21.

[12] N. V. Gusev, S. V. Lyapushkin, M. V. Kovalenko (2011) / Automation of technological complexes and systems in industry: a textbook / N. V. Gusev, S. V.Lyapushkin, M. V. Kovalenko; Tomsk Polytechnic University. - Tomsk: Publishing house of Tomsk Polytechnic University, 2011 - p. 198

[13] Denisenko V.V. (2009) / Computer control of technological process, experiment, equipment / V. V. Denisenko, Moscow: Hotline-Telecom, 2009. -608 p. 47.

[14] Denisenko V.V. (2009) / Computer control of technological process, experiment, equipment / V. V. Denisenko, Textbook. Stavropol: AGRUS publ., 2009. 100 p. 48.

[15] Minaev, I. G. (2009) / Programmable logic controllers. Practical guide for a novice engineer / I. G. Minaev, V. V. Samoylenko-Stavropol: AGRUS, 2009. - 100 p.

[16] Gost R IEC 61131-3-2016 programmable Controllers. Part 3. Programming languages (IEC 61131-3: 2013, IDT). - M.: Standartinform, (2016), 230 p. (in Russian).

[17] Gost R IEC 61508-1-2007 Functional safety of electrical, electronic, programmable electronic systems related to safety.:Standartinform, (2008), 58 p. (in Russian). 
[18] Gost 27.301-95. Reliability in technology. Calculation of reliability. Basic provisions-Moscow: publishing house of standards, (1995)-19 p.

[19] Gost 27.310-95. Reliability in technology. Analysis of the types, consequences, and criticality of failures. Basic provisions-Moscow: publishing house of standards, (1997)- $12 \mathrm{p}$.

[20] Gost 26.013-81. Measuring and automation tools. Electrical signals with a discrete change of parameters input and output. - M.: Standardinform, (1983)-7 pages.

[21] Gost 15971-90 System of information processing. Terms and definitions. Moscow: publishing house of standards, (1990), $14 \mathrm{p}$.

[22] RD 03-418-01. Guidelines for conducting risk analysis of hazardous production facilities. Normative documents of Gosgortehnadzor of Russia-Moscow: publishing house of standards, (2001)-10 p.

[23] Pryanichnikov V.E., Chernyshev V.V., Arykantsev V.V., Aryskin A.A., Eprikov S.R., Ksenzenko A.Ya., Petrakov M.S. (2018). Enhancing the Functionality of the Groups of Autonomous Underwater Robots // Proceedings of the 29th DAAAM International Symposium, 2018. — DAAAM International, Vienna, Austria, 2018. — P.1319-1325. DOI:10.2507/29th.daaam.proceedings.190.

[24] Pryanichnikov V. E., Aryskin A. A., Ksenzenko A. Ya., Petrakov M. S., Ignatiev V. A., Khelemendik R. V. (2018) / Construction of a service Autonomous mobile robot based on control using logicalanalysis of the realizability of operations // Scientific service on the Internet: proceedings XX All-Russian scientific conference (September 17-22, 2018, Novorossiysk). Moscow: IPM im. M.In.Keldysh, 2018. DOI:10.20948/abrau-2018.

[25] Pryanichnikov V.E., Aryskin A.A., Eprikov S.R., Kirsanov K.B., Khelemendik R.V., Ksenzenko A.Ya., Prysev E.A., Travushkin A. S. (2017). Technology of Multi-Agent Control for Industrial Automation with Logical Processing of Contradictions, Proceedings of the 28th DAAAM International Symposium, pp.1202-1207, B. Katalinic (Ed.), Published by DAAAM International, ISBN 978-3-902734-11-2, ISSN 1726-9679, Vienna, Austria. DOI:10.2507/28th.daaam.proceedings.167.

[26] Pryanichnikov V.E., Aryskin A.A., Eprikov S.R., Kirsanov K.B., Khelemendik R.V., Ksenzenko A.Ya., Prysev E.A., Travushkin A. S. (2017). Technology of Multi-Agent Control for Industrial Automation with Logical Processing of Contradictions // Proceedings of the 28th DAAAM International Symposium, 2017. — DAAAM International, Vienna, Austria, 2017. - P.1202-1207. DOI:10.2507/28th.daaam.proceedings.167.

[27] V.E.Pryanichnikov, A.Ya.Ksenzenko, S.V.Kuvshinov, Yu.S. Marzanov, Yu.V.Poduraev, E.A.Pryses, R.V.Khelemendik, A.A.Ariskin, O.O.Belyaev, P.A.Bryzgalov, D.V. Davydov, D.A.Kuzovkin, P.F.Pletenev, S.R.Eprikov. (2016) / The development of a network of robotarium and mobile robots "Amur" for innovative learning intelligent robotronica. C.141-148. // Proceedings of the International multiconference of Network partnership in science, industry and education. Saint Petersburg, Russia 4-6 July 2016. "Politehnika-Service", 2016, Peter the Great Saint Petersburg Polytechnic University, 2016. ISBN 978-5-906841-54-4.

[28] Official site of the company "Siemens" [electronic resource]: Official site of the company "Siemens" - access Mode: https://www.siemens.com/global/en/home.html(accessed 08.12.2019).

[29] Official site of the company "National Instruments" [electronic resource]: Official site of the company "National Instruments" - access Mode: http://www.ni.com/ru-ru.html(accessed 07.12.2019).

[30] The official Russian-language site of the software product ISaGRAF of Rockwell Automation [electronic resource]: the Official Russian-language site of the software product ISaGRAF of Rockwell Automation-access Mode: http://www.isagraf.ru/(accessed 10.01.2020).

[31] Official portal of the Modbus developers Association [electronic resource]: Official portal of the Modbus developers Association-access Mode: http://www.modbus.org/(accessed 07.12.2019).

[32] Poduraev Yu. (2000) / V. Fundamentals of mechatronics / Yu. V.Poduraev, M.: IC MSTU "Stankin", 2000. -103 p.

[33] Egorov O. D., Poduraev Y. V., Bubnov M. A. (2016) / Robotic mechatronic systems / O. D. Egorov, Yu. V. Poduraev, M. A. Bubnov, M.: MSTU " STANKIN, 2016. - 326 p. (in Russian).

[34] Pryanichnikov V. E. (2008) / The Combination of ultrasonic data filtering and linear drive software control / Pryanichnikov V. E.// Devices+automation. -2008. - №12, 22-29-c. 